\title{
INSTANTÁNEAS SOBRE EL GRAFFITI MEXICANO: HISTORIAS, VOCES Y EXPERIENCIAS JUVENILES
}

TANIA CRUZ SALAZAR*

\begin{abstract}
RESUMEN
Este artículo habla de la emergencia del graffiti y la cultura juvenil en torno a él en la ciudad de México. Para ello recurro a distintas imágenes generacionales que han servido como iconos de lo joven y la manera de ser joven. Al particularizar a esta cultura juvenil retomo imágenes de contexto sociocultural que permiten entender el carácter del graffiti. Presento un breve recuento histórico del graffiti estadounidense y mexicano que toma como nodos de producción a la ciudad de Nueva York y más tarde a la ciudad de México. Finalmente armoniza al recorrido de la emergencia del graffiti las distintas voces de los integrantes de colectivos de grafiteros.
\end{abstract}

PALABRAS CLAVE: GRAFFITI, IDENTIDAD Y CULTURA JUVENIL

* Doctora en Antropología Social. Profesora invitada en la Universidad Libre de Berlín y posdoctorante de El Colegio de la Frontera Sur, San Cristóbal de Las Casas, México. E-Mail: tcruzs@ecosur.mx. 


\title{
RESUMO
}

Este artigo trata da emergência do graffiti e da cultura juvenil associada ele na cidade do México. Para isto, recorro a distintas imagens geracionais que servem como ícones do jovem e a maneira de ser jovem. Ao particularizar esta cultura juvenil, retomo imagens do contexto sociocultural que permitem entender o caráter do graffiti. Apresento um breve histórico do graffiti norteamericano e mexicano, que toma como modelos de produção a cidade de Nova York e mais tarde a cidade do México. Finalmente, as diferentes vozes dos integrantes de coletivos de grafiteiros juntam-se ao itinerário da emergência do graffiti

PALAVRAS CHAVE: GRAFFITI, IDENTIDADE E CULTURA JUVENIL

\begin{abstract}
This article talks about the origins of the Mexican graffiti and the youth culture around it. I use different generational images that represent youth icons and the way of being young. I also bring in to play images of the sociocultural context that show the birth of graffiti writers and particularize this youth culture. I do a briefly history of Nortamerican and Mexican graffiti which take the cities of New York and Mexico as points of cultural production. Finally the graffiti writers voices take place to talk about their constitution or their own experience in the youth scene.
\end{abstract}

KEY WORDS: GRAFFITTI, IDENTITY AND YOUTH CULTURE 
El recuerdo es como un perro que se acuesta donde le place.

(Noteboom, 2006:14)

\section{IMÁGENES JUVENILES Y GENERACIONALES}

ENTRE LOS RECUERDOS MÁS elaborados en torno a los jóvenes están aquellos que los vieron nacer como íconos contraculturales, vanguardistas o alternativos. Los jóvenes obreros, los estudiantes, los músicos, los literatos... Ilustraron los tiempos de las primeras juventudes personajes que en cierta manera dejaron la escena detrás de bambalinas y pasaron a ser mediáticos: Arthur Rimbaud a través de Kerouac y Burroughs, Marylin Monroe y Presley, Bob Dylan, Andy Warhol, Lou Reed, Bob Marley, Jean-Michel Basquiat, entre muchos más.

Las prácticas que nacieron a la par de la juventud como etapa de preparación y disfrute del tiempo de ocio permitieron el florecimiento de culturas alternas a la sociedad en general. En la década de los cincuenta la proliferación de juventudes diversas se dio a conocer por tener estilos de vida, filosofías y actitudes particulares. El contexto sociopolítico internacional de los años sesenta y setenta se caracterizó por grandes movilizaciones juveniles que dejaron huella en la historia mundial: el movimiento estudiantil y obrero de Francia (mejor conocido como el Mayo Francés que paralizó al país amenazando al gobierno gaullista), la masacre del 68 en México (que dejó a miles de estudiantes desaparecidos y asesinados por constituir una lucha social frente al gobierno de Díaz-Ordaz), las manifestaciones pacifistas estadounidenses en contra de la Guerra de Vietnam, entre otras más.

Estos movimientos no sólo agruparon a juventudes con visiones de mundo particulares sino que también definieron estilos de vida sui generis, p. e. en los cincuenta la generación beat, en los sesenta los hippies y en los setenta los punks por solo mencionar algunos. Recordemos que las críticas al contexto político mundial provenían de las generaciones juveniles de aquel entonces, en los 40 y 50 los beat recrearon imágenes en torno a la liberación espiritual y sexual, el gusto por el jazz, la literatura, los viajes y, en general, la afición por el modo de vida oriental, especialmente la concepción de mundo. Los hippies con las consignas de amor y paz promovieron la práctica de una vida natural al margen del consumo conspicuo esto como elemento clave en contra del sistema capitalista; una bandera que divulgó la imagen de un sujeto radical, partidario de la vida en comunas, del consumo de 
drogas naturales como la marihuana, los hongos, la mezcalina, el peyote aunque también del LSD. Los hippies crearon la imagen del joven despreocupado, tranquilo, vestido cómodamente, sin afecciones ni pretensiones, luciendo afros, cabellos y barbas largas. Por su lado, los punks de la década de los 70 criticaron el convencionalismo social utilizando la música como herramienta de crítica - bandas como Los Ramones, Sex Pistols y los New York Dolls fueron representativos de estas agrupaciones juveniles - en donde se exponía de manera agresiva la inconformidad al status quo. Esta concepción de mundo también perfiló un estilo basado en el lema «Do it yourself» el cual proponía tomar literalmente y metafóricamente de la basura o de las piezas inservibles; objetos o pensamientos que pudieran ser reciclados para producir culturalmente otros objetos como revistas caseras, atuendos, discos compactos, etc.

Estas imágenes generacionales han sido mundialmente interpeladas por varios de los movimientos y agrupaciones juveniles que se han configurando en los años subsecuentes y han sido utilizadas como estandartes de lo subcultural en tanto juvenil. Para el caso que aquí ocupa es importante hablar de una serie más de imágenes espaciotemporales que perfilan la emergencia del graffiti mexicano porque constituye el hilo conductor del discurso juvenil sobre los orígenes de éste. Es una serie de imágenes espaciotemporales de orden sociopolítico que ayudan a entender la manera en que los gratiferos trazan geográficamente las raíces de su práctica juvenil.

\section{IMÁGENES SOBRE LOS ORÍGENES DEL GRAFFITI}

En Estados Unidos la mayor oleada de inmigrantes a nivel histórico y mundial — 40 millones de personas - tomó lugar entre 1819 y 1995. Las comunidades más establecidas a lo largo de estos años llegaron a ser la africana, la latina y la asiática. Este fenómeno dio pauta a una serie de posturas radicales en torno a los inmigrantes vistos como 'amenazas' para la nación y la cultura estadounidense. La creencia de que «la presencia de inmigrantes de Centroamérica y el Caribe podía deteriorar 'el balance étnico' norteamericano ya que, al no integrarse al melting pot 'las instituciones, los valores y las tradiciones norteamericanas' se verían en peligro» fue una percepción que hasta la actualidad ha permanecido (Marciel, 1994:39).

Con la crisis económica de 1929, muchos agricultores norteamericanos migraron a las ciudades pero la mitad de los trabajadores indus- 
triales vivía ya en la pobreza. Nueva York, Boston, Chicago y San Francisco eran ciudades industrializadas pero también fragmentadas. Mientras se podía disfrutar de maravillosos museos, universidades y bibliotecas públicas, existían crecientes suburbios en donde se gestaron los barrios bajos 'infestados' de población negra y latina. Durante los procesos de industrialización y reindustrialización, la llegada de migrantes rurales nacionales, de migrantes internacionales y la recepción de éstos a las ciudades produjo una distorsión sociocultural (De Diego, 1997).

En varias ciudades, jóvenes negros y radicales lideraron agitaciones que rechazaban tácticas pacifistas ineficaces para la defensa de los derechos fundamentales como la del religioso Martin Luther King. El asesinato de este personaje en Memphis, Tennessee, en 1968, desencadenó motines raciales en más de cien ciudades. Fueron incendiados distritos comerciales en barrios negros y muchas personas fueron asesinadas. Siguiendo el ejemplo de los negros, otras minorías como los latinos, asiáticos, indígenas y homosexuales exigieron una ampliación $\mathrm{y}$ respeto de sus derechos.

Hacia fines de los años 60, se volvieron más evidentes las implicaciones políticas de esta interacción cultural entre una nueva generación de negros y portorriqueños. El movimiento pro derechos civiles y la lucha de liberación negra dio origen a la organización del partido Young Lords (Flores, 1984:37).

Para finales de la década de los sesenta las agrupaciones juveniles conocidas como gangs o 'gangas' en el este de Los Ángeles estaban en su apogeo. ${ }^{1}$ Jóvenes negros, latinos, asiáticos, caribeños, europeos y demás se congregaban en bandas para defender el barrio o el guetto en donde vivían. Las pugnas callejeras eran constantes. El acceso a las drogas, el robo, la prostitución, las carencias de todo tipo y el racismo eran parte de su cotidianeidad. Los jóvenes negros y portorriqueños compartieron entonces sentimientos de pertenencia y se agruparon en bandas, crews de grafiteros y colectivos de break dancers o rapers (Flores, 1986).

1 Gang es una palabra inglesa que significa banda. Ésta es utilizada para denominar a las bandas callejeras juveniles. Sobre el tema hay muchos estudios que profundizan la dinámica de las bandas como el clásico «Street Corner Society» de William Whyte Foot, «Barrio Gang» de Diego Vigil, «Wallbangin' Graffiti in L. A.» de Susan Phillips y en México «En la calle otra vez» de Rossana Reguillo y «La banda rifa» de Rogelio Marcial. 
Es en este contexto que El Bronx presenció un nuevo fenómeno: el bombardeo grafitero sobre los vagones del metro neoyorkino. Con diseños innovadores, coloridos, indescifrables pero significativamente grandes las bombas - letras dibujadas en forma de nubes que versan el nombre del crew o del grafitero - abarcaron de inicio a fin todos los trenes. Eran dibujos o mensajes raros, pintados a escondidas, en horas nocturnas y, por personajes desconocidos. Cuando el graffiti de los vagones del metro paso a las paredes de la ciudad adquirió otras técnicas y estilos, las firmas, que eran trazos en un solo color eran el nombre del writer, el número de la calle o casa en dónde vivían para ser contactados si era necesario (Flores, 1986; De Diego, 1998).

Para 1980 la expansión de esta práctica tomó lugar a nivel nacional en el país norteamericano. A través de la música y, en especial, del hip hop, el graffiti y otras expresiones callejeras neoyorquinas se convirtieron en la moda de los adolescentes estadounidenses de los guettos. A mediados de esta década varios son los viajes que realizaron los writers $^{2}$ neoyorquinos a galerías europeas, el hip hop ganaba popularidad y la cultura callejera de Nueva York empezó a despertar interés en muchos lugares por lo que un movimiento global se formaba para ese entonces como «parte de una cultura juvenil que incluyó a artistas, break-dancers, raperos, mezcladores de música, entre otros» (Chalfant, 1987:8).

En breve, la atmósfera que nutrió de rebeldía a distintas manifestaciones artísticas en Estados Unidos tanto al muralismo chicano en San Diego y San Francisco, como el graffiti neoyorkino y las expresiones callejeras como el hip hop, el rap y el break dance estuvieron orientadas a exponer la violencia urbana (crimen, droga, cárcel, represión). Es así como el graffiti surgió en un país lleno de contradicciones, discriminación racial, cultural, exclusión social y económica (Flores, 1986:34-40).

En Europa las primeras expresiones que utilizaron el aerosol como herramienta para la manifestación pública tiene antecedentes en el movimiento francés de mayo de 1968 que fue propiciado por estudiantes quienes estaban en contra del sistema educativo el cual tenía como prioridad graduar a una gran cantidad de estudiantes sin prepararlos para los espacios laborales que les esperaban. Los jóvenes convocaron a una huelga general, hubo protestas estudiantiles por todas partes pero éstas fueron enfrentadas por la policía. El sindicato de obreros los apoyó y más tarde esta manifestación aglomeró a millones de personas, este mo- 
vimiento se convirtió en una manifestación en contra del régimen de Charles de Gaulle, primer presidente de aquel país. En Berlín, las primeras 'pintas' fueron a inicios de los $70 \mathrm{y}$ tomaron lugar en el muro. Las pintas usaban aerosol negro y tenían un punto de vista crítico sobre la división entre Alemania oriental y occidental, ¡Hasta cuándo separados! ¡Esto es inhumano!, un par de años más tarde, aún antes de la caída del muro, la mezcla de colores en las producciones sobre éste tomaron lugar a la par de las fiestas, los picnis y las distintas formas de apropiación de este espacio por jóvenes que se reunían de uno u otro lado. El boom del graffiti en Europa fue un década más tarde (Vigara, 1989).

En América Latina fueron las ciudades de Bogotá, Río de Janeiro, Caracas, Buenos Aires y la Ciudad de México los primeros lugares que presenciaron este tipo de expresión juvenil. En los países sudamericanos el término para denominar al graffiti fue el de 'pintada'. En el México de los años sesenta el graffiti monocromático fue conocido como 'pinta'. Aquellos mensajes que regularmente tenían una connotación política, poética o humorística, al igual que Francia, constituyeron las pintas de los jóvenes estudiantes del 68. Las bandas callejeras de los ochenta las nombraron 'pintas' mientras que en el norte del país las conocían como 'placas'o 'placazos'. No es hasta finales de los ochenta y principios de los noventa que los jóvenes definieron a sus pintas como graffiti.

En los imaginarios juveniles mexicanos, las pinturas rupestres, las inscripciones de las culturas Maya, Zapoteca, Olmeca o Azteca representan también las raíces del graffiti contemporáneo mexicano. El movimiento artístico de los años 20 conocido como Muralismo ha sido una enérgica fuente de inspiración para los grafiteros urbanos de hoy día, ya que éste tuvo como objetivo la creación de obras monumentales para el pueblo en contraposición a las obras de caballete destinadas a galerías. Diego Rivera, José Clemente Orozco y David Alfaro Siqueiros, los grandes muralistas del momento, dieron a conocer una nueva forma de asaltar las calles con la socialización de sus obras. Éste es uno de los espíritus que pervive en muchos de los jóvenes grafiteros, que después de haber ensayado en la escena ilegal, ahora son ahora muralistas y sólo pintan de manera legal.

\section{HISTORIAS Y LEYENDAS SOBRE EL ARRIBO DEL GRAFFITI A LA CIUDAD DE MÉXICO}

A finales de la década de los setenta los jóvenes de colonias populares de la ciudad de México, comúnmente conocidos como 'chavos banda', 
agrupados en colectivos de más de veinte individuos del mismo barrio en las esquinas, las calles o cuadras; eran quienes rayaban paredes con aerosol para delimitar el territorio de la banda a la cual pertenecían y perpetuar su adscripción barrial. El bote de aerosol y la pinta, se convirtieron en herramientas de control territorial, ocasionando conflictos juveniles por el reconocimiento de límites espaciales. 'El tachón' de unos sobre otros era motivo de ofensa, enfado y pleitos callejeros. Éstas fueron las características que particularizaron a las agrupaciones juveniles de principios de 1980 «el arte moderno del spray llegó a México en la década de los ochenta, como una manifestación de protesta y delimitación de territorios entre las distintas bandas de la capital, a la cabeza [estaban] Los Pachintos, cuyos integrantes eran oriundos del barrio Tacubaya» (Revista Temas del Mundo, 2001:4).

Otras expresiones de este tipo y con el mismo sentido aunque con referentes disímiles fueron surgiendo en las calles del norte de la ciudad. Las placas de los cholos - jóvenes que han intercambiado, adoptado y resignificado de manera directa elementos de la cultura chicana en la constitución de sus colectivos llamados clica - con el afán de delimitar su territorio y defender el barrio, plasmaron la placa de la clica. Entre las producciones más elaboradas están los murales que regularmente solo utilizan el color negro y que tienen iconos católicos: la Virgen de Guadalupe, el nombre Lupita, Cristos y ángeles. ${ }^{3}$

Entre los chavos banda que pintaban placazos en sus colonias y los cholos que se dedican a pintar monocromáticamente sus murales y placas, surgen aquellos dedicados a rayar paredes: los taggers. ${ }^{4}$ Varios son los jóvenes quienes afirman que el graffiti, desde su nacimiento hasta la aparición en la capital mexicana, responde al recorrido de las siguientes

3 Los cholos son jóvenes mexicanos con estilos americanizados, congregados en pandillas delimitadas territorialmente por el barrio al cuál pertenecen. Gustan de raparse la cabeza, vestir guango, usar paliacates y lentes oscuros grandes. Los cholos experimentan de manera constante la violencia con amenazas, golpizas y hasta asesinatos. La identidad chola refiere al orgullo de ser mexicano, representado en la fe católica, el origen prehispánico y en la adscripción territorial «por mi madre vivo y por el barrio muero» es el lema del cholo. El cuerpo conforma otro espacio de representación simbólica tatuado con símbolos y signos de la identidad chola, los tres puntos que forman un triángulo y que representan 'la vida loca', el nombre manuscrito de 'La Lupita' y el nombre de la clica p. e. 'Sur 13'.

4 Escritor de graffiti dedicado a firmar ilegalmente con plumón, ácido, etiqueta o aerosol cualquier superficie. 
ciudades: Nueva York - Los Ángeles - Tijuana - Guadalajara - Ciudad Nezahualcóyolt y Ciudad de México. Las ciudades mexicanas que tienen inicialmente contacto con estas expresiones juveniles guardan una característica peculiar, para el país fueron polos de desarrollo a nivel industrial en la década de los 70. De manera que si contextualizamos la emergencia de estos actores juveniles con el ámbito socioeconómico e histórico del país mexicano, la relación del proceso de urbanizaciónmodernización de estas ciudades y en especial, la ciudad de México, con la segregación espacial y social es la constante (Tamayo, 1998). Esto último lo experimentó el grueso de la población y de manera particular, el sector juvenil, que para aquél entonces se convertiría en 'población de riesgo' por estar desempleada y gozar de un prolífico tiempo libre.

Cuando llegó la cruda petrolera con sus obvias consecuencias económicas, en las ciudades del país se escenificaron las primeras batallas simbólicas juveniles; en Tijuana los placazos de los cholos marcaron la raya del «barrio rifa»; en Monterrey, los cholombianos dibujaban sus placazos góticos en la colonia Independencia; en Guadalajara, los guanatocholos afirmaron su presencia con placazos en todos los espacios públicos; $y$ en la ciudad de México los chavos-banda demarcaban sus barrios con pintas multicolores para expresar sobre los escenarios urbanos la presencia de la primera generación juvenil desmaderna (Gaytán,2000:79).

Los jóvenes de ciudad Nezahualcóyolt agrupados para bombardear las paredes y retar a cualquier autoridad fueron los primeros en este oficio. Desde entonces los más conocidos en el mundo del graffiti han sido el Fly, el Joker, el Sketch, el Humo, el Crater, el Venus, el Killer, el Koka y el Aztec, personajes que representan estandartes para todos los grafiteros en la ciudad. Algunos de ellos han emigrado al extranjero en busca de espacios y estilos innovadores otros se por ofertas laborales y, otros más, han seguido el camino de la pintura artística y se quedan en México para actualizar sus técnicas estudiando pintura al óleo, muralismo, expresionismo, realismo, otras. Los relatos del Killer, un veterano en el mundo del graffiti, nos dicen al respecto:

Empecé como en el noventa o en el 89, igualmente empezó el Koka y su primo el Aztec que antes ponían Balam y Rat. Balam era el Koka y Rat su primo el Aztec, ahorita ese chavo es tatuador, ellos empezaron y a mí me jalaron porque pues a mí me llamó la atención. Yo fui el tercer LEP ((Libertad en el Paraíso o Libertad de Expresión en Pintura o de un Pueblo) que entró y en ese tiempo no había movimiento de graffiti éramos nada 
más nosotros tres de Iztapalapa y obviamente en ese momento llevábamos año y medio. Dos años antes los más viejos eran el Fly y el Sketch. En aquel entonces el Fly era el que nos vendía las válvulas, los plumones y el Sketch ya llevaba un montón de años en esta onda porque iba mucho a Guadalajara. Si nos ponemos a pensar en los orígenes del graffiti éste viene del norte hacia acá, empezó en Tijuana por los ochentas y estuvo ahí hasta los noventas cuando fue su apogeo, luego ya se vino para acá que empezó el desmadre por el 92 al 95 más o menos, hasta el 2000 cuando todavía estaba algo bueno (Entrevista al Killer, 2003).

A principios de los noventa la ciudad de México experimentó el florecimiento de la cultura juvenil en torno al graffiti, las producciones grafiteras empezaron a ser más prolíficas en toda la ciudad. Iztapalapa, Pantitlán, Constitución, Coyuya, entre otras áreas ubicadas en las orillas de la ciudad fueron las primeras en reunir tanto firmas grafiteras como colectivos de taggers. Para aquél entonces no existía una variedad de estilos, sino más bien se reducían a firmas y bombas, ya que el objetivo de los grafiteros era pintar su clave en la mayor cantidad de espacios posibles de manera ilegal y riesgosa. Con el paso de los años y el intercambio de información entre jóvenes que compartían esta forma de expresión, hubo grafiteros que venían de Guadalajara a la ciudad de México cargando libretas llenas de estilos de firmas: con flechas, letras encimadas, acostadas, con estrellas, con burbujas. También hubo quienes viajaban al norte del país - Tijuana - o al sur de Estados Unidos - San Diego y Los Ángeles-y otros más que venían del gabacho. ${ }^{5}$ Muchos estilos se fueron retomando, otros transformando y finalmente expandiendo en toda la ciudad.

Era el año de 1995 cuando el boom del graffiti invadió la ciudad. Toda esa generación juvenil llamada 'de la crisis' por su apatía política, ausencia de un proyecto a futuro e incredulidad ante las políticas gubernamentales tomó como icono al Movimiento Zapatista del 94 el cual les representó un símbolo de rebeldía y protesta contra el neoliberalismo. Muchos grafiteros simpatizaron con los ideales del movimiento revolucionario zapatista a la par de una gran cantidad de jóvenes universitarios que se incluyeron como seguidores del pro-neozapatismo. La idea para

5 El gabacho es cualquier otro lugar del extranjero. Regularmente la palabra se utiliza para nombrar al lugar o a la persona que es originaria de Estados Unidos, pero la mayoría de la población mexicana, también utiliza la palabra para referirse a la persona extranjera que habla otro idioma y que tiene un fenotipo anglosajón. 
entonces de los grafiteros pro-zapatistas fue crear conciencia de la situación económica, social y cultural del país a través de sus experiencias directas con la privatización de espacios juveniles, realizando murales y producciones que tuvieran temas específicos en contra del racismo cultural, de la pobreza, de la desigualdad de géneros, entre otros temas más.

El boom del graffiti se caracterizó porque la producción era cada vez más compleja y porque eran cientos de jóvenes quienes salían en las noches y en las madrugadas para pintar el metro, los bancos, las casas o los puentes peatonales y espacios 'calientes', es decir, espacios muy vigilados que imponían un reto adicional, el burlar a las autoridades. Eran muchos los crews que competían por el premio de «ser reconocidos por la chaviza de writers» a través de sus huellas en la arena del graffiti. Entre los crews más populares estaba el AMX (Artistas Mexicanos Extremos), el SF (Sin Fronteras) que pintaban en el Parque Vía por Azcapotzalco empezando desde el puente de Viga en el Estado de México, área que abarca desde la colonia El Rosario hasta la torre de PEMEX en circuito interior. También estaban los A (Aztlán), los FME (Fucking Mother Epifania) quienes rayaban en Atizapán, Satélite, Lomas Verdes y parte de Tlalnepantla. Para ilustrar la dinámica juvenil de los grafiteros de aquél entonces las palabras del Killer constituyen una excelente demostración:

Por ahí del 94 hacíamos unas juntototas. Eramos un buen de banda, como treinta cabrones del LEP ¡sí, éramos un chingo! Nada más que de ahí se fueron saliendo los que hacíamos realismo, los que eran bombers y todo eso porque sí habían bombers, taggers y pieleros, es decir, los pieleros éramos los que ya hacíamos producciones mas acá, más complicadas con una combinación de las anteriores. Tuvimos problemas con los CHK (Kids Hate Cops o los niños odian a los policías) y tuvimos problemas porque fueron nuestros enemigos de aquel tiempo. Es que los CHK eran bombers y nosotros éramos pieceros, entonces esos güeyes siempre nos metían calabaza y a parte de nuestro crew nos traicionaron ¿conociste a un crew famoso el 5K? [me pregunta] Pues en un tiempo se juntó el LEP el SF — que el SF fue el que nos pidió paro a nosotros, no sé qué pedo tuvieron - entró el ERA (Existe, Resiste y Ataca), el SNK y el UFE eran los crews del $5 k$ y el plan era aplastar a todos los CH hasta que tuvimos treguas, se hizo un desmadre, se madrearon ahí en Pantitlán o sea que terminó el pedo en putazos hasta que quién sabe qué pasó (Entrevista al Killer, 2003). 
Para aquel entonces los grafiteros hacían sus propias herramientas de manera muy rudimentaria porque aún no existía la expropiación de esta cultura y su masificación en productos culturales redituables para las industrias. Así que las válvulas, las crayolas de distintos colores en una sola barra, los plumones de ácido, entre otras herramientas no estaban a la venta. Para lograr los distintos tipos de trazos lo que ellos hacían era extraer los atomizadores de botellas de perfume, de los sprays para el cabello para aplicárselos a los botes de pintura en aerosol. Las crayolas en prismas, eran elaboradas manualmente por los mismos grafiteros. Tomaban un tubo de metal y en él derretían cuantos colores quisieran, de manera que cuando pintasen las líneas de la firma estarían coloreadas como arcoiris. Otra de las técnicas empleadas en aquel entonces para lograr una línea gruesa sin tener la válvula adecuada era tomar algún bote de pintura de zapatos vació y rellenarlo con pintura liquida del color deseado. Al utilizarlo presionándolo contra la superficie en donde se pintaba, se obtendría una línea suficientemente gruesa en comparación a las de las válvulas hechas con los atomizadores de perfumes y sprays.

Cuando las producciones de graffiti empezaron a publicarse por los mismos jóvenes quienes retrataban sus obras para comprobar su eficacia y así ser aceptados en los crews a los cuales deseaban pertenecer, el graffiti se volvió una moda. Revistas, vídeos, cómics y fanzines comenzaron a ser vendidos, distribuidos e intercambiados entre este sector juvenil. ${ }^{6}$ De esta manera los diversos crews y grafiteros de distintas y lejanas partes de la ciudad de México se conocieron. Por ello, el reconocimiento de 'los mejores' se intensificó y expandió a estos medios de comunicación.

Del 95 al 2005 el graffiti se origina una interesante y rápida expansión de esta expresión juvenil a lo largo de la república mexicana. Muchos adolescentes de las primarias y secundarias han sido atraídos por la cultura juvenil grafitera. Rayar con aerosol y plumones en los baños, en las aulas, en las paredes de las instituciones educativas ha sido un común denominador. Desde el norte al centro y del centro al sur, el territorio mexicano presencia escrituras en aerosol sobre muros de ciudades grandes y pueblos pequeños en donde hasta las paredes de adobe cuentan con una marca de graffiti.

6 El fanzine, es una revista casera, muchas veces elaborada con letra de molde y dibujos a mano, los jóvenes las fotocopian y así las distribuyen. 


\section{INSTANTÁNEAS CONTEMPORÁNEAS: VOCES Y EXPERIENCIAS DE JÓVENES GRAFITEROS}

Las instantáneas que presento a continuación están conformadas por imágenes de algunos crews que fueron y son parte de la escena grafitera en la ciudad de México. Las voces y experiencias de distintos miembros de estos crews permiten entender la conformación de los imaginarios juveniles en torno al graffiti.

Los LEP. Alrededor de 1987 este colectivo fue formado por el Koka y el Aztec quienes ocho meses más tarde invitarían al Epidem, el tercer miembro de este crew. El Epidem, es el hoy afamado Killer, quién al lado de aquellos se dedicó a taggear gran parte de la ciudad de México. A pesar de provenir de la delegación Iztapalapa, ellos buscaron los lugares más recónditos y peligrosos de la ciudad y así demostraron que estaban listos para morir y dejar huella de su existencia. «Lo que sea de cada quién, tuvimos el mejor récord rayando la ciudad. Fuimos hasta buscados por la policía» (Entrevista al Killer, 2003). En ese tiempo no había tantos crews ni grafiteros, éstos fueron de los primeros en dar a conocer esta práctica juvenil y a difundirla. Un par de años más tarde cuando la presencia de otros crews surgió en la escena urbana, los conflictos tanto de adscripción territorial como de reconocimiento y fama promovieron la competencia entre grafiteros. Llegar a ser popular y arriesgado era y sigue siendo una de las características del 'buen grafitero' del 'rifado' del 'chingón'. Los crews de aquel entonces también tenían problemas por las diferencias en los estilos de las producciones, mientras que los LEP se dedicaban a hacer piezas los CHK realizaban sólo bombers. Las piezas son letras más elaboradas, tienen más colores y formas complicadas, mientras que las últimas son letras infladas y rellenas con un mismo color. La diferencia radicaba en la experiencia en el arte del spray, puesto que una pieza es una obra más complicada de hacer y requiere de más tiempo y práctica. Para principios de los noventa surge una agrupación de crews conocida como el 5K, que significaba cinco crews. El LEP, el SF, el UFE, el SNK y los ERA, conformaron este colectivo sólo para lograr deshacer la cohesión del crew CHK. Por la mala relación que tenían y las constantes competencias, sus diferencias terminaron en golpes, pero el $5 k$ no logró su objetivo.

Hueko: Lo que no lograron cinco crews, dos pendejos de mismo CHK lo hicieron, se pelearon a madrazos y ahí es cuando valió madres el CHK y eso por un rato, pero la neta aún están grafiteando juntos. Mira, se tu- 
vieron que unir cinco crews para uno solo y no la armaron [termina riéndose el Hueko, ex-miembro del CHK].

Killer: ¡vete a la verga pendejo la neta los chingamos! [miembro del LEP]. Hueko: [en tono burlón] pero no lograron su objetivo, nos la pelaron (Entrevista al Hueko y al Killer, 2003).

Los AC (Always Cunning) en español Siempre Astutos. Este crew fue uno de los más reconocidos en toda la ciudad de México. Se formó en 1997. Por su larga y especial trayectoria, este colectivo se ha ganado el respeto de la mayoría de novatos y veteranos del graffiti. Fueron de los primeros en pintar bombas y vomitados y se volvieron famosos por hacerlo en lugares muy atrevidos como empresas importantes, avenidas peligrosas - periférico, viaducto, avenida Tlalpan - puentes, vagones del metro y terrenos baldíos. Su placa fue única por aquel entonces, puesto que ellos tuvieron la iniciativa de poner la palabra familia en inglés debajo de las siglas del crew «AC family».

Este crew desde inicio fue muy unido y después de diez años de haber aparecido en la escena del graffiti seguir juntos ha sido un reto. Su intención de constituir una familia de cuates se logró gracias a la constancia de sus reuniones y sus prácticas de solidaridad. Iniciaron con aproximadamente 25 integrantes pero con el tiempo fueron desertando varios. Las reglas para ser aceptado a este colectivo eran tener una buena relación con todos los integrantes del crew, pintar con calidad, dar algunas fotos para demostrar el trabajo realizado y pintar de manera excesiva en diversas partes de la ciudad. Aquellos que causaban conflictos o tuvieran diferencias con algunos de los miembros del crew son expulsados del grupo. Antes, se convocaba a una junta y ahí se nominaban a los posibles expulsados, todos opinaban y después decidían quien saldría o no. Muchos de ellos fueron despedidos por tener otro tipo de pensamiento al de la mayoría y querer imponer sus ideas. En el 2003 aun los mismos miembros decidían permanecer o aislarse del crew y hacen pública su decisión cuando se encuentran con los otros integrantes. El crew AC para ese entonces contaba con aproximadamente quince integrantes, de ellos, lo más conocidos eran el Set, el Picues, el Yate, el Huber, el Tenk, el Catom, el Heart y el Tyrek.

Los DID (con Dignidad sin Ignorancia y sin Dogmas) integrado por el Sear, el Ober, el Liso, el Cinco, el Akus, el Linki, el Hisek y el Frosk. El DID se formó en el año 2000, los muchachos ya se conocían y muchos de ellos pintaban solos pero fueron invitados por sus amigos a participar en este colectivo. Tanto el Sear como el Ober son jóvenes 
de 23 años que dejaron de estudiar la preparatoria a los 18 años, viven en la colonia Santo Domingo y les gusta pintar de manera ilegal. Son especialistas en el estilo bomber. Su crew es muy conocido pero sólo en la zona sur de la ciudad, en los alrededores de las estaciones del metro Universidad, Copilco y Miguel Ángel de Quevedo. Estos dos jóvenes han pintado muchas veces de manera legal porque también pertenecen a otros crews de legales uno de ellos es el FUNE (Formando Una Nueva Expresión). El Sear y el Ober fueron de los primeros que conformaron el crew Formando Una Nueva Expresión y regularmente se reúnen con los jóvenes que llegan a pintar los domingos a la Parroquia de la Resurrección ubicada en la Avenida Aztecas de la Colonia Santo Domingo en la delegación Coyoacán.

Los JA, Jóvenes con Arte, fue formado por el Dócil y sus cuates. Eran jóvenes que pertenecían a dos distintos crews, el VIH (Vastal Ilegal Habits, en español Bastardos con Hábitos Ilegales) y el UMK (Underground Mexican Kinas, en español Reyes Subterráneos Mexicanos) que tenían tiempo de conocidos pero que no todos se dedicaban al arte del aerosol. Formaron este colectivo para perpetuar sus relaciones amistosas. La mayoría, vivía en la misma colonia y se conocían desde que eran niños. Más tarde se mezclaron con otro crew que lleva el mismo nombre pero que pertenece a la zona de Iztapalapa y ahora comparten el nombre aunque no los espacios ni las relaciones.

El FUNE es un colectivo juvenil que nació a principios del 2002 y se consolidó en junio del mismo año, con la iniciativa de un jesuita perteneciente a la Parroquia de la Resurrección, quién coordina el trabajo con jóvenes de esta orden religiosa. Entre los objetivos primordiales de esta pastoral juvenil estuvo: i) consolidar una organización de jóvenes grafiteros que pudiese vincular su forma de expresión con los problemas sociopolíticos, ii) sensibilizar a la comunidad en general con sus producciones, iii) favorecer la creación artística impartiendo clases de dibujo y de graffiti y iv) canalizar sus inquietudes hacía el arte, impartiéndoles clases de óleo, aerografía y aerosol. Para diciembre del 2001 el jesuita Jorge Atilano contactó a grafiteros de las colonias Ajusco-Coyoacán y Pedregal de Santo Domingo para iniciar este crew. Conoció a uno de los grafiteros más populares de la zona, el Dócil, quién al ser invitado a participar en este proyecto dando clases de graffiti en un taller que tendría lugar en la parroquia aceptó de manera entusiasta e invitó a otros grafiteros, entre ellos, a la muy amafada grafitera Farsa. Ante la convocatoria de asistir a clases de graffiti impartidas por estos dos grafiteros son varios los jóvenes que asistie- 
ron. El 27 de enero del 2002 se llevó a cabo la primera sesión y los chavos cooperaban con $\$ 10.00$ pesos para recibir la instrucción adecuada. Al cabo de un mes la asistencia bajó y quién impartía las clases se fue desanimando por la poca remuneración que recibía. Tanto el Dócil como la Farsa fueron alejándose de este proyecto, asistiendo así de manera esporádica a las reuniones y a las clases, sin embargo, nuevos integrantes empezaron a llegar al punto de encuentro cada fin de semana. Para marzo del mismo año se consolidó un fuerte núcleo de jóvenes que vivían muy cerca de esta parroquia, el Bomit, el Doper, el Drawer, la Due, el Teick y otros. La iglesia se convirtió en un lugar acogedor para aquellos jóvenes interesados en pintar. Los apoyos por parte de la iglesia llamaron la atención de los chavos, puesto que había latas de aerosol gratis, bardas disponibles y uno que otro incentivo más.

Varios grafiteros que tenían tiempo de estar pintando de manera ilegal y que además guardaban una trayectoria indiscutible dentro del mundo grafitero, llegaron a las clases. Éstos pertenecían a distintos crews de la zona, sin embargo, su interés por mejorar las técnicas y por intercambiar puntos de vista con el Dócil y otros, fue lo que les llamó la atención.

Para junio del 2002 eran el Dócil, el Killer, el Sear, el Kopia, el Seick y la Due quienes lideraban al grupo de grafiteros. Estos empezaron a conseguir espacios para pintar de manera conjunta y legal, cuestión que fue permitiendo la cohesión grupal. Hicieron algunos viajes fuera de la ciudad de México hacia otros lados de la república, en donde de manera organizada pintaban murales. Estos acercamientos dieron pauta a que se formara una amistad estrecha entre varios del grupo y finalmente - respondiendo a la propuesta del jesuita Jorge Atilano- eligieron un nombre que los identificó como los FUNE. Para finales del 2003 todavía el Killer, el Sear, el Kopia, el Drawer, el Keno, el Obles, el Sheik, la Due, el Doper, el Sower, el Cler eran quienes más frecuentaban a la parroquia que servia de punto de encuentro en los FUNE.

Como vemos la variedad de crews y sus integrantes recurren a distintas experiencias e imágenes para recrear la concepción colectiva que hace posible la práctica común y el sentimiento de pertenencia a la cultura juvenil grafitera. La manera en que se apropian, resignifican y desarrollan una expresión que tiene carácter mundial, marca el sentido de sus actos en el marco del mundo de las juventudes urbanas. Instantáneas que permiten dar cuenta de la efervescencia de la pluralidad de mundos juveniles urbanos. 


\section{IMÁGENES PÓSTUMAS}

Leer las historias en las paredes de los baños públicos recrea guiones de puestas en escena que nunca tomaron lugar más que de manera escrita en un espacio tan privado como lo es un baño público ¡qué paradoja! Recuerdo que en la secundaria me tomaba el tiempo para leer los anuncios rayados con pluma o clavo hechos en 'las paletas' de las sillas en donde tomaba clases. Desde entonces, una infinidad de mensajes y trazos han asaltado mis ojos cuando me topo con tallos labrados, vidrios rayados, paredes pintadas que anuncian «algo».

El graffiti tiene la peculiaridad de irrumpir la mirada de los ciegos, justo porque acude a otro tipo de sensibilidades e inscribe experiencias colectivas de jóvenes que gustan de un mismo estilo. Sea un trazo hecho a mano sobre una superficie compacta o un dibujo estilizado sobre una playera, el cuerpo u otro lugar; el graffiti cuenta con una lógica intersticial de la vida juvenil. El graffiti usado como un término genérico de cualquier grabado, escrito o dibujo hecho sobre vidrio, muro, metal, textil, madera $u$ otra superficie tiene la particularidad de abarcar hasta lo inimaginable en la escena extraoficial de comunicación.

Actualmente, el graffiti, constituye un movimiento mundial. Su presencia abarca recónditos espacios de cualquier población. Es un fenómeno muy complejo que contiene diversas facetas y tipologías. El graffiti como forma de comunicación permite la interacción de una sociedad juvenil que pasa por alto conscientemente las condiciones y normas de la sociedad en la que habitan. Éste guarda símbolos lingüísticos que hablan de colectividad, soledad, valor y búsqueda. La palabra crew indica la agrupación grafitera a la que se pertenece, por ejemplo, cuando un escritor firma una pared escribe su nombre de grafitero y después las siglas de su crew. La firma, revela sólo ante los ojos de quienes son grafiteros: i) presencia, ii) autoría y ii) pertenencia al grupo; p. e. Killer, LEP crew. El Killer es una firma que contiene el nombre de quien es miembro del crew o colectivo de grafiteros LEP, siglas que como he explicado antes significan Libertad en el Paraíso. La firma indica la presentación del actor en la vida cotidiana es adueñarse de un 'spot'. La palabra one que también pertenece a la lengua inglesa y significa 'uno' es utilizada para obtener reconocimiento individual sobre el colectivo. Escribir la palabra one después de la firma otorga un valor añadido el de ser un 'ganador' porque se está pintando sólo sin compañía de otro miembro más del crew. El grafitero que pinta sólo es atrevido y valiente, ya que prescinde de acompañantes o 
el respaldo del colectivo para inscribirse en la escena del graffiti. Un grafitero que agrega one al final de su firma también puede estar buscando la atención de los colectivos más famosos y espera ser llamado a formar parte de uno de ellos. Sin embargo, en el mundo del graffiti es posible pertenecer a varios crews a la vez.

Como se observa, la influencia directa del movimiento grafitero de Estados Unidos fue indiscutible en el movimiento grafitero de México. Es por ello que en la jerga grafitera mexicana existen palabras que no son traducidas al español o que no son propuestas desde el español para denominar actos, sujetos y objetos claves. La manera en que la palabra graffiti se convierte en un término genérico a nivel mundial es explicado por Ana Vigara (1996) cuando afirma que con la internacionalización del grafiteo «se consolida el término graffiti como designación de todo mensaje mural (con o sin contenidos verbales, con o sin voluntad estética), invariable tanto para el singular como para el plural: la $-i$ final pierde así su carácter morfemático de número y queda reducida a un simple indicativo de procedencia en casi todos los idiomas» (p.2).

Lo mismo sucede con la palabra writer que fue designada por primera vez en los años 60 en Estados Unidos para hablar de aquellos que pintaban en los guettos de Manhatan, el Bronx y demás ciudades norteamericanas en donde las bandas delimitaban sus territorios con pintas barriales. En la ciudad de México esta palabra fue adoptada para identificar a aquellos taggeadores, firmadores, escritores o grafiteros dedicados escribir graffiti y no dibujarlo. Pudo haber sido otro sustantivo que se adaptara mejor o que pudiera recuperar toda esa complejidad de la comunicación, el arte y la resistencia que guarda el graffiti, sin embargo esta reproducción de los significados de la práctica juvenil tiene que ver con la actualización de la cultura juvenil grafitera a nivel mundial. Por ello, toda la jerga del graffiti norteamericano ha sido apropiada por los grafiteros mexicanos para conformar su léxico. Aunque a la práctica la denominan 'pintar' o 'grafitear' el producto es reconocido de acuerdo a los estilos norteamericanos impuestos en el graffiti: master piece - obra maestra, producción o pieza, cómic - caricatura, tag - firma, throw up - vomitados, Hubble - bombas, three $d \mathrm{~s}$ - tridimensionales o deltas, wildstyle - estilo salvaje, murales, stickers o etiquetas, stencils o plantillas, entre otros.

La instantánea final nos dibuja una metrópoli tamizada por prácticas grafiteras que edifican y transforman la concepción del ser joven a nivel mundial. Situación que permite visualizar el enlace entre la 
ciudad-global y la cotidianidad juvenil, en donde las identidades colectivas se conforman y reconfiguran diariamente. En este sentido, las subjetividades de los jóvenes interaccionan y se integran, formando personalidades e identidades de acuerdo al contexto generacional que los rodea y que a su vez dialoga con generaciones previas.

SAN CRISTÓBAL DE LAS CASAS (MÉXICO), FEBRERO 2008

RECIBIDO: MARZO 2008

ACEPTADO: ABRIL 2008

\section{REFERENCIAS BIBLIOGRÁFICAS}

Ávila LANDA, Homero y TANiA CRUZ SAlAZAR (2006): «Juventudes en la posmodernidad mexicana del siglo XXI». Jóvenes, Año 10, №24. México: IMJ.

Castleman, Craig (1982): Getting Up: Subway Graffiti in New York. New York: The Massachusetts Institute of Technology. (1982): Los graffiti. Madrid: Hermann Blume.

Chalfant Henry y Martha CoOper (1985): Subway Art. New York: Henry Holt \& Co, publisher.

- y JAMES PRIGOFF (1987): Spraycan Art. New York: Thames \& Hudson.

CRUZ SALAZAR, TANIA (2004): «Yo me aventé como tres años haciendo tags. ¡Si, la verdad, sí fui ilegal! Grafiteros: arte callejero en la ciudad de México». Revista Desacatos N $\mathrm{N}^{\circ} 14$. México: CIESAS.

(2003): «Voces de colores. Graffers, crews y writers: identidades juveniles en el defeño metropolitano». Tesis de maestría. México: CIESASCentro.

_ (2008): «Mudándose a muchacha. La emergencia de la juventud en indígenas migrantes». México: CIESAS-Sureste (en prensa).

CuENCA, Álvaro (2003): «Graffiti para promocionar». Revista Graffiti Arte Popular $\mathrm{N}^{\circ} 11$. México: Corporativo Mina.

De CerTAU, Michel (1996): La invención de lo cotidiano 1: Artes de hacer. México: Universidad Iberoamericana.

De Diego, Jesús (1997): «La estética del graffiti». En Departamento de Historia del Arte, Universidad de Zaragoza, ultima actualización, versión consultada: (www.positivos.com).

DíAz CRuZ, Rodrigo (2002): «La creación de la presencia. Simbolismo y performance en grupos juveniles». En ALFREDO NATERAS (coordinador): Jóvenes, culturas e identidades urbanas. México: UAM-I/Miguel Ángel Porrúa. 
FeiXa, Carles (1998): El reloj de arena. Culturas juveniles en México. México: SEP y Causa Joven.

(1995): «Tribus urbanas y chavos banda. Las culturas juveniles en Catalunya y en México». Nueva Antropología №47. México.

(1988): La tribu juvenil. Una aproximación transcultural a la juventud. Torino: Edizioni L'Occhiello.

et al. (2002): Movimientos juveniles en la Península Ibérica. Graffitis, grifotas, okupas. Barcelona: Ariel Social.

FiguerOA, FERNANDO (1998): «La calle como espacio extraoficial de comunicación y expresión estética: del adoquín al aerosol». Ponencia en Jornadas de Historia del Arte Contemporáneo 1968-1998: 30 años de contracultura, 21 de abril, Facultad de Bellas Artes de la Universidad Complutense de Madrid.

FLORES, JUAN (1986): «Rap, graffiti y break. Cultura callejera negra y puertorriqueña en Nueva York». Cuicuilco $\mathrm{N}^{\circ} 17$. México.

Foote Whyte, William (1973): Street Corner Society. The social structure of an italian slum. Chicago: The University of Chicago Press.

GAYTÁN SANTIAGO, PABLO (2000): «Sombras cromáticas en el archipiélago urbano. Pintas, tags, graffiti». Revista de Estudios Sobre Juventud, Nueva Época, Año 4, №11. México: IMJ.

MARCIEL, DAVID (1994): El bandolero, el pocho y la raza. Imágenes cinematográficas del chicano. México: UNAM-The University of New México.

NATERAS DOMíngueZ, AlFredo (2002): «Las identificaciones en los agrupamientos juveniles urbanos: grafiteros y góticos. En Sociología de la identidad. México: Miguel Ángel Porrúa-UAM-I.

Nooteboom, Cees (2006): Cómo ser europeos. Madrid: Biblioteca de Ensayo, Ediciones Siruela.

PHILLIPS, SUSAN (1999): Wallbanggin' Graffiti and Gangs in L. A. Chicago: The University of Chicago Press.

Reguillo Cruz, Rossana (1995): En la calle otra vez. Las bandas: identidad urbana y usos de la comunicación. México: ITESO.

Revistas Temas del Mundo (2000), México.

RodríGUEZ, MARIÁNGela (1998): Mito, identidad y rito. Mexicanos y chicanos en California. México: CIESAS-Miguel Ángel Porrúa.

Silva, ARMANDo (1989): «La ciudad como comunicación». Diálogos de la Comunicación $\mathrm{N}^{\circ} 23$. FELAFACS.

(1987): Punto de vista ciudadano: focalización visual y puesta en escena del graffiti. Bogotá: Instituto Caro y Cuervo.

(1986): Graffiti: una ciudad imaginada. Bogotá: Universidad Nacional de Colombia.

SOTO RAMíREZ, JUAN et al. (1997): «Dilemas contemporáneos de la identidad y lo Juvenil. Territorialidad, modernidad y cultura». Jóvenes, Cuarta Época, Nº4. México: IMJ. 
TAMAYO, SERGIO (1998): «La práctica de la ciudadanía en la redefinición de la modernidad y las utopías urbanas». Sistemas urbanos, actores sociales y ciudadanía. México: Colección de Estudios Urbanos, Área de Estudios Urbanos, CYAD, UAM-A.

VAlenZuela ARCE, MANUEl (1997): Vida de barro duro: cultura popular y juvenil y graffiti. México: Universidad de Guadalajara-COLEF.

— (1992): «Identidades culturales: comunidades imaginarias y contingentes». En MANUEl VALENZUela ARCE (coordinador): Decadencia y auge de las identidades. Cultura nacional, identidad cultural y modernización. México: COLEF.

- (1988): ¡A la brava ése! Identidades juveniles en México: cholos, punks $y$ chavos banda. México: El Colegio de la Frontera Norte.

Vigara TAuste, ANa María y PACo Reyes (S/F): «Graffiti y pintadas en Madrid: arte, lenguaje y comunicación». En: www.graffiti.org.

Villafuerte, FERNANDO et al. (1987): Las bandas en tiempo de crisis. México: Nueva Sociología.

Villela, SAMUel (1995): «Trazos de identidad. Pintura mural en el contexto bicultural México-EUA». Cuicuilco, Volumen 2, Nº5.

\section{ENTREVISTAS}

CruZ SAlaZAR, TANiA, Entrevista al Killer, grafitero del crew FUNE, LEP y Rwasa, 2003.

—_, Entrevista al Hueko, grafitero del CH, DID, 2003.

— - Entrevista al Ober, grafitero del PK y el DID, 2003.

_ E Entrevista al Sear, grafitero del DID, 2003. 